\title{
Seems Fair to Me: Dyadic Leader Consensus Mediates Fairness and Group Performance
}

\section{Dritjon Gruda', Jim McCleskey², and Raul Berrios ${ }^{3}$}

\begin{abstract}
Drawing on both relational and shared leadership theory and utilizing social consensus, we examine the relationship between percieved leader fairness, leader consensus (LC), and group performance. We do so by conceptualizing $L C$ as a new way of hypothesizing and examining shared leadership. LC derives from mutual dyadic perceptions of all members in a team. First, we examine perceptions of leader fairness as a possible antecedent of LC. Second, we investigate the mediational effect of dyadic perceptions of leadership (i.e., LC predicts group performance). In two multisource studies using a round-robin design, we demonstrate that when team members reach a clear consensus about their team leader, perceived leader fairness was positively associated with LC. Furthermore, teams who perceived their leaders as fair exhibited higher group performance.
\end{abstract}

\section{Keywords}

leader, consensus, fairness, performance, team

'EMLYON Business School, Ecully, France

${ }^{2}$ Western Governors University, Salt Lake City, UT, USA

${ }^{3}$ Universidad de Santiago de Chile, Chile

\section{Corresponding Author:}

Dritjon Gruda, EMLYON Business School, 23 Avenue Guy de Collongue, Ecully 69130,

France.

Email: gruda@em-lyon.com 
What does it take to be a legitimate leader in the eyes of others? How do we determine who is the leader of a particular group? Although the research on leadership characteristics, including leadership styles and trait determinants of leadership (Glynn \& Raffaelli, 2010), is an important block in the construction of a comprehensive theory, a growing body of literature conceptualizes leadership as an interpersonal process of influence (Bass, 1990; Podolny, Khurana, \& Hill-Popper, 2005). Relational leadership theories have defined leadership as an emergent property of groups that result from mutual influence (e.g., Carson, Tesluk, \& Marrone, 2007; Uhl-Bien, 2006). Thus, leadership has come to be understood as a social phenomenon that is grounded in collective arrangements, and dynamically configured to produce one or more individuals perceived as leaders by the group (i.e., hierarchically defined). Given the increased emphasis on views of leadership as a relational phenomenon (Graen \& Uhl-Bien, 1995; Uhl-Bien, Graen, \& Scandura, 2000), the question arises as to the nature of the social process through which leadership is created and distributed within groups.

The emergence of leadership and the legitimacy of those leaders have occupied the leadership literature for some time (Judge, Bono, Ilies, \& Gerhardt, 2002; Yukl, 2009) and have evolved into the complexity leadership theory. In this article, we provide empirical evidence as to the validity of complexity leadership theory using a new conceptualization of leadership perception, which we label leader consensus (LC).

Complexity leadership theory (Uhl-Bien, 2006; Yammarino, Salas, Serban, Shirreffs, \& Shuffler, 2012) indicates that there are three key components in the emergence of leadership within groups: (a) relative position of the members in formal hierarchy, (b) mutual perceptions of abilities, and (c) dyadic relationship patterns between team members (Yammarino et al., 2012). From these three processes, relative position in formal hierarchy has been the most commonly discussed indicator of leadership (Marion \& UhlBien, 2003). However, mutual perceptions of abilities and dyadic relationship patterns between team members are the cornerstones required to define leadership as a dynamic system of relationships.

Given the importance of nonhierarchical determinants in relational theories of leadership, we examine shared leadership as a form of $\mathrm{LC}$, that is, a form of social consensus (Pearce, Conger, \& Locke, 2008), derived from dyadic patterns of perceptions of leadership prototypicality between members, as suggested by complexity leadership theory (Uhl-Bien \& Marion, 2008). To the best of our knowledge, the studies presented in this article are the first empirical examination of LC within the complexity leadership theory literature. 
In Study 1, we examine whether perceptions of leader fairness in groups contribute to the perception of leadership. There is a large body of research showing that fairness creates more favorable judgments of authority (see Tyler \& Lind, 1992), which in turn contributes to the legitimacy of managerial leaders. In other words, fairness contributes to the view of legitimate leaders as role models, which in turn strengthens positive perceptions of the leader. In this article, we test whether perceptions of leader fairness can predict perceptions of leadership, conceptualized as LC among team members. In this approach, LC is defined as the degree to which group members tend to systematically agree on team members' leadership prototypicality. We operationalize LC using the social relations model (SRM; Kenny, 1994; Kenny \& Lavoie, 1984). We test the main associations in the present research using the SRM and aggregation methods to compare the separate contributions of these approaches. Furthermore, we provide a preliminary test of the utilization of the SRM to evaluate LC.

Understanding leadership as a relational function in groups is nontrivial in terms of organizational outcomes. In fact, consistent evidence has shown that, for example, shared leadership (a specific relational leadership theory; Uhl-Bien, 2006) is positively related to group performance (Sivasubramaniam, Murry, Avolio, \& Jung, 2002). Therefore, in Study 2, we investigate whether LC mediates the relationship between perceived leader fairness (PLF) and group performance.

\section{Shared and Relational Leadership}

Considering the interpersonal nature of leadership, it becomes clear that differences in leadership between individuals are not exclusive to the domain of trait theories (i.e., certain people possess a higher level of intrapersonal characteristics, which increases their effectiveness as leaders). Leadership may instead be the result of consistent perceptions of team members regarding the leadership qualities of several members of a group. In this article, we conceptualize shared leadership within teams as a collective form of leadership (Contractor, DeChurch, Carson, Carter, \& Keegan, 2012; Cullen, Palus, Chrobot-Mason, \& Appaneal, 2012; Yammarino et al., 2012), with multiple team members performing leadership roles at the same time (Carter \& Dechurch, 2012). Shared leadership theory allows for the existence of more than one leader at a time and is not confined by an exclusively leader-centric perspective (Drescher \& Garbers, 2016). Therefore, relational leadership is a dynamic social system inseparable from the relationships between team members (Gronn, 2002; Yammarino et al., 2012). This idea is consistent with recent conceptualizations emphasizing that leadership increases to the extent 
that one or more individuals are perceived as the right or best person to lead a group (DeRue \& Ashford, 2010; DeRue, Nahrgang, \& Ashford, 2015; Sanders \& Schyns, 2006; Schyns, 2006). Based on Hollander (1993), DeRue and Ashford (2010) argued that leadership is not something that leaders possess, but rather something that leaders and followers create by mutual endorsement. As collective leadership allows multiple team members to execute leadership, this type of leadership is a more interactive form of team member involvement and acknowledgment (Fletcher \& Kaufer, 2003). This allows team members to respond to an increasingly complex work environment (Pearce, Yoo, \& Alavi, 2004). Shared leadership also has been found to relate positively to organizational performance and satisfaction scores (D’Innocenzo, Mathieu, \& Kukenberger, 2016; Wang, Waldman, \& Zhang, 2014).

Relational leadership and its close cousin, network theory, relate conceptually as both evolved from LMX (Graen \& Graen, 2006; Graen \& Uhl-Bien, 1995). In LMX, each leader-follower relationship is unique, varies in quality, and exists as a dyad (Anand, Hu, Liden, \& Vidyarthi, 2011). Shared network theory inherits from LMX the understanding of leadership as a relational, dyadic process. However, shared network theory adds the importance of leadership emergence through relational processes. Leadership results from a social process of influence that creates coordination, roles, goals, and relationships (Uhl-Bien, 2006).

Complexity leadership theory also views leadership as a socially constructed emergent phenomenon (Uhl-Bien, 2006). Using a complexity leadership approach assumes that leadership is built on complex, adaptive, dynamic systems in which individual team members depend on each other to achieve a common goal or mission (Yammarino et al., 2012). Complexity leadership defines leadership, not just by individual team members themselves (i.e., their various abilities and perceptions of each other, and their central position within the team), but also accounts for the dyadic relationships (i.e., patterns of influence between team members). Essentially, this approach assumes that the relationships individual team members form with each other can contribute to overall perceptions of leadership within a team. Therefore, the unique social relations among team members define leadership. This approach allows for the examination of leadership as consistent perceptions of others on the leadership qualities of one or more members of a group. In this article, we outline and examine the importance of this approach with regard to the linkages between perceptions of leader fairness and LC. 


\section{Rationale for Social Consensus as a Leadership Measure}

One challenge when conceptualizing leadership as an emergent, socially driven process concerns appropriately capturing the dyadic nature of leadership. Some research circumscribed within relational leadership theories has addressed this task by estimating leadership at the team level, using different forms of aggregation, or more depurate forms of measurement based on social network analysis (Ensley, Hmieleski, \& Pearce, 2006; Pearce \& Sims, 2002). Despite common use of the aggregation method (Mathieu \& Chen, 2011) and the use of standard deviations (Schyns, 2006) to measure consensus, there are several drawbacks in these methods, including missing important sources of variance at the dyadic level (D'Innocenzo et al., 2016).

Previous aggregation studies have focused on hierarchical leadership configurations (Ensley et al., 2006; Pearce et al., 2004; Sivasubramaniam et al., 2002), and ignored informal teams with no appointed leader (D'Innocenzo et al., 2016). Another form of aggregation used in previous research has relied on the standard deviation of team members' perceptions of relevant leadership characteristics (Sanders \& Schyns, 2006; Schyns, 2006). This is a more refined estimation of relational leadership because it considers mutual perception within teams to estimate a form of leadership emergence based on the degree of dispersion of leadership evaluations. As noted above, using standard deviation as an indicator of the degree of LC has several limitations. First, standard deviations are sensitive to the skewness of sample distributions due to the squares of the deviations. Second, standard deviation computations ignore the amount of variability in dyadic behavior that can be attributed to the individual, dyadic, or group level of analysis. Therefore, this approach ignores the inherent nonindependence observed in interpersonal constructs, such as leadership.

\section{Social Networks}

The social network approach is another way of examining shared leadership (Carson et al., 2007; D'Innocenzo et al., 2016; Mehra, Smith, Dixon, \& Robertson, 2006). Here, scholars study the configural constructs that make up a team. Using this approach, team member scores are not converged or averaged, but rather account for the distribution of relational influences between team members (Mehra et al., 2006). This social network approach also has certain drawbacks. First, team level density is essentially an aggregation measure of team members' individual shared leadership density scores (D'Innocenzo et al., 2016). It does not capture and contribute to the understanding of patterns of 
influences. In teams where more than one leader emerges, the network theory approach does not apply, as it assumes one central leader (Yammarino et al., 2012). Finally, networks are assumed to be stable over time (Brass, 1984; Brass, Galaskiewicz, Greve, \& Tsai, 2004), although relationships, and, in particular, work relationships, can be very dynamic.

\section{Consensus}

One conceptual alternative is the use of consensus as a preferred approach in team decision-making (Pearce et al., 2008). Consensus involves estimating the degree to which multiple members agree about the leadership characteristics of one or more members of a group, over and above other social processes such as idiosyncratic evaluations of others, and personal preferences for one or more members of a group (e.g., friendship). Thus, an ideal measure of consensus should estimate whether one or more members gathered sufficiently positive perceptions from other team members to be considered the leader.

Therefore, to appropriately capture mutual perceptions of leadership occurring within teams, it is necessary to consider a scenario where team members' perceptions of each other's leadership are modeled in a way that makes it possible to disentangle the portion of variance corresponding to the degree of agreement across team members with respect to each given target. Accordingly, we endorse the SRM (Kenny, 1994; Kenny \& Lavoie, 1984).

SRM. The SRM is an interpersonal model that has been used extensively to investigate behavior occurring in mutual dyadic interactions, such as attraction and personality impressions (Back \& Kenny, 2010).

Using the SRM, Livi, Kenny, Albright, and Pierro (2008) conceptualized leadership as a multilevel construct that operates at the group, person, and dyadic level of analysis. They argued that differences between individuals relating to how much each member of a group is perceived as a leader are a distinct operationalization of leadership at the individual level. Furthermore, they showed those differences can be meaningfully distinguished as leadership operating at the group (differences in leadership among groups), dyadic (idiosyncratic perception between some members of a group), and individual level of analysis (i.e., differences between individuals in how much leadership they perceive in others; assimilation). Reinforcing our notion of leadership as consensus, Livi et al. (2008) reanalyzed evidence from seven previous round-robin design studies using the SRM and found that about $48 \%$ of the variance was attributed to $\mathrm{LC}$, indicating that a relevant portion of the interpersonal perceptions of leadership in groups lies in the eye of the beholder. 


\section{Leader Fairness and LC}

Fairness is a common heuristic people use to judge individuals in the workplace (Janson, Levy, Sitkin, \& Lind, 2008). Facing organizational environments beset by tensions and facing conflict between the benefits and drawbacks of investing time and effort in multiple relationships, individuals make use of heuristics to help them judge their coworkers and navigate the organizational setting (van Knippenberg, De Cremer, \& van Knippenberg, 2007).

Previous studies have proposed that justice treatment or perceptions of fair treatment relate positively to employees' perceptions of the leader-follower relationship. Leaders choose whether they engage in fair treatment with their followers, and this influences not only followers' perceptions of their leader but also their own fair treatment with others (Folger \& Cropanzano, 1998). Reciprocating this behavior then impacts followers' organizational citizenship behavior as well as job satisfaction and performance. Some support for this proposed model has been found (Colquitt et al., 2013), in which the authors used a structural equation model examining meta-analytic results of the relationship between justice perceptions and performance, mediated by the leader-follower relationship. In addition, Cropanzano, Prehar, and Chen (2002) utilized a mediation model similar to the one we propose in this article, indicating that relational leadership acts as a mediator between fair treatment and job performance. In short, a leader-follower relationship of high quality is likely to increase the relationship between justice perceptions and various outcome variables (Masterson \& Lensges, 2015), as employees are likely to be motivated to reciprocate that same fair behavior. In this article, we extend these findings further. We focus on the impact of PLF and observations of LC on group performance as an organizational outcome. First, we know that leaders perceived as fair by their followers build better relationships, and engender more positive attitudes including job satisfaction and organizational commitment (Masterson, 2001). These leaders also increase positive emotions, and more desirable behavior such as task performance and cooperation while reducing undesirable behaviors such as deviance and retaliation (Masterson \& Lensges, 2015). The fair treatment of others, that is, interactional justice, is the strongest of all four justice dimensions (CohenCharash \& Spector, 2001), while the supervisor is the source of fairness perceptions in the overall group (Burton, Sablynski, \& Sekiguchi, 2008). Therefore, we focus on the perceptions of fair treatment with regard to the team leader.

Second, we acknowledge that the leader-follower relationship does not exist in a vacuum. Therefore, it is likely that other dyadic relationships, 
between the leader and other followers or between followers themselves, influence perceptions of fair treatment (Henderson, Liden, Glibkowski, \& Chaudhry, 2009; Masterson \& Tong, 2015). We view these dyadic relationships through the lens of LC because consensus includes both follower-follower relationships and leader-follower relationships. As noted previously, prior research argues that fairness creates more favorable judgments of authority (see Tyler \& Lind, 1992). These favorable judgments contribute to the legitimacy of group leaders. In other words, fairness contributes to the view of leaders as role models, which in turn strengthens positive perceptions of the leader. Furthermore, we argue that within groups or teams without formal leaders, multiple leaders can emerge to share leadership. We conceptualize shared leadership as a form of $\mathrm{LC}$, that is, a form of social consensus (Pearce et al., 2008), derived from dyadic patterns of perceptions of leader behaviors between group members, as suggested by complexity leadership theory (Uhl-Bien \& Marion, 2008). This leads us to the first hypothesis.

Hypothesis 1: Leader fairness positively relates to LC.

\section{LC and Group Performance}

Past research has also stressed the link between different theoretical contributions related to relational leadership (e.g., shared leadership) and team performance (Avolio, Jung, Murry, \& Sivasubramaniam, 1996; Hoch \& Kozlowski, 2014). Several meta-analyses have confirmed these previous findings (D'Innocenzo et al., 2016; Nicolaides et al., 2014; Wang et al., 2014). Theoretically, the more leadership is shared among team members, the higher individual team members' involvement in the team and the more positive the outcomes for these individuals. However, it is important to keep in mind that shared leadership is an informal and internal process (D'Innocenzo et al., 2016; Morgeson, DeRue, \& Karam, 2010). Shared leadership assumes the distribution of leadership among team members is dynamic and emergent (Avolio et al., 1996; Carson et al., 2007).

A recent meta-analysis by D'Innocenzo et al. (2016) found that in 3,198 teams (published and unpublished), there is also a clear difference of effect sizes, depending on the measurements of shared leadership. For example, studies applying a network approach or similar measures of shared leadership result in higher effect sizes than studies applying an aggregation approach. Clearly, there is an empirical difference. However, the theoretical difference (i.e., whether team members are asked to evaluate the team, or all team members individually) still stands. If shared leadership is defined not merely by individual team members' abilities and attitudes but also by their dyadic 
interactions with their team peers, these interactions need to be considered empirically as well (D’Innocenzo et al., 2016). They likely contribute to the distribution of leadership and the informal assignment of leadership roles within the team (Contractor et al., 2012; DeRue, 2011) and likely have an impact on performance. Therefore, using the complexity leadership approach, we hypothesize the following:

Hypothesis 2: LC positively relates to team performance.

\section{Mediational Effect of LC}

In our article, we take a step toward examining the previously proposed model of fairness and performance while considering the social context of teams (Lavelle, Rupp, \& Brockner, 2007; Masterson \& Lensges, 2015). Previous research indicates that teams composed of trusting and respectful team members are more likely to achieve high levels of team performance (Day, Gronn, \& Salas, 2004; Marks, Mathieu, \& Zaccaro, 2001). Shared leadership influences this process positively (Carson et al., 2007; Erez \& Isen, 2002; Pearce \& Sims, 2002), and distributed leadership among team members is more likely to contribute to better functioning team dynamics and subsequently higher team performance. We therefore hypothesize the following:

Hypothesis 3: LC mediates the relationship between leader fairness and team performance.

\section{Study I}

In Study 1, we utilized a round-robin design to evaluate the relationship between PLF and LC, as well as the association between LC and group performance in nonrandomized teams using SRM and aggregation methods. This study also provides a variance partitioning analysis to demonstrate the importance of employing the SRM.

\section{Methodology}

Procedure and sample. In the first study, we used a sample of students working in teams from the beginning of the semester. All students were part of an undergraduate business program. Six groups were formed, each of which consisted of six or seven members. Data for this study were collected in two parts over a period of approximately 1 month. At Time 1, all students reported their grade point average (GPA) and demographics. Data collected at Time 2 
included measures on consensus and fairness. Overall, the sample consisted of 38 participants $\left(55 \%\right.$ female, $M_{\text {age }}=21.3$ years; $S D=0.83$ years $)$. We explained the purpose of the study to the students and assured their confidentiality and anonymity. Informed consent was provided to all participants; however, they were only told that the study was on the nature of team dynamics rather than specifically being told about the researchers' interest in fairness and leadership emergence to avoid any tendency toward social desirability bias when rating their peers for leadership qualities. Once the informed consent form was read, signed, and returned, we provided each team and student with an individual ID comprised of their team letter and individual number.

In these project teams, a variety of leadership behaviors occurred including setting a schedule for and organizing team meetings, conducting a skills inventory among the team members, breaking the project up into parts and assigning those parts to the student members, and following up with those members to ensure a timely completion of those parts.

Data analysis. In this study, leadership was assessed using a round-robin design based on within-group ratings of leadership characteristics. To appropriately model the inherent dependency resulting from this design, a SRM (Kenny, 1994; Kenny \& Lavoie, 1984) for indistinguishable dyads (i.e., members of each group cannot be distinguished from one another by some variable, such as gender) was initially used. This design allowed us to decompose the variance and determine the hypothesized associations between PLF and LC, including trait-based control measures. Multilevel modeling (MLM) was employed to analyze the data because of the nonindependence of the data structure. The data structure includes the individual level of analysis (i.e., actor and partner), the dyadic level of analysis (i.e., multiple evaluations of each member), and the group level of analysis (each working group). This type of data creates a cross-classified data structure.

The SRM distinguishes three fundamental observable phenomena in every interpersonal interaction. A portion of the total variance in dyadic behavior is due to individual-level effects. Within these individual-level effects, it is possible to separate the following two common phenomena: the individual tendency to perceive others stereotypically (i.e., assimilation; Kenny, 1994) and the individual tendency to be perceived consistently across a group of individuals (i.e., consensus; Kenny, 1994). For example, in a group of workers, assimilation captures the tendency for members to rate other group members as similar with regard to leadership (everybody is either a good or a bad leader). In contrast, consensus reflects the level of agreement across team members regarding the leadership characteristics of one or more members 
(everybody agrees that person " $\mathrm{X}$ " is a good leader or a bad leader). In addition, the SRM estimates the portion of variance due to the specific relationship between two individuals (e.g., Ann's behavior with Jo is unique; Kenny, 1994).

We estimated the SRM actor, partner, and relationship variance without predictors using random intercepts for actor, partner, dyad, and group (Kenny \& Livi, 2009). The intraclass correlation (ICC) for group members' reports on leader characteristics (i.e., partner variance) was interpreted as a meaningful indicator of LC.

In a second step, individual scores of LC were computed based on the estimation of partner effects, following the formulas by Kenny, Kashy, and Cook (2006). This computation creates a continuous measure of LC based on the degree to which each individual in a group received more favorable (or unfavorable) evaluations from others. Then, the associations between LC and perceived fairness and group performance were estimated using MLM. Finally, these associations were compared with aggregation methods at the group level and using standard deviations. These analyses were run using simple regression models given that both aggregation methods dispense with the nonindependence resulting in the dyadic data structure.

Measures. Data collected included LC, PLF, and team performance.

LC. LC was assessed using Cronshaw and Lord's (1987) General Leadership Impression Scale. As this is a student population, we replaced "superior" with "leader." Participants were asked to evaluate each member of their team except themselves. Sample items include the following: "To what degree does this person fit your image of what a leader should be?" "How much leadership does this person exhibit?" The scale is based on a 5-point Likerttype scale from 1 (none) to 5 (a lot). The internal consistency alpha was good $(\alpha=.93)$. As some participants left some questions unanswered, the total number of observations for Study 1 was $k=204$.

PLF. The measure for perception of leader fairness was derived from Ambrose and Schminke's (2009) measure of perceived overall justice (POJ) built upon both Lind, Kray, and Thompson (2001) and Colquitt and Shaw (2005). Perceived organizational justice includes two dimensions: individuals' personal justice experiences and fairness of the organization in general (Ambrose \& Schminke, 2009). We were mostly interested in the perceived overall fairness or general feelings of justice with regard to the team leader. Hence, we chose three items to determine the leader's perceived degree of fairness, after replacing "unit supervisor" with "team leader" and replacing "unit 
employees" with "team members." This was done due to the nature of the sample, as our participants were students instead of actual employees. This scale was comprised of the following items: (a) "Overall, team members are treated fairly by their team leader," (b) "In general, team members can count on their team leader to be fair," and (c) "In general, the way team members are treated by their team leader is fair." Participants scored their agreement with each item on a 7-point scale $(M=6.59, S D=0.63)$ ranging from 1 (strongly disagree) to 7 (strongly agree). The alpha for POJ was 77.

Team performance. Team performance was scored on a scale from 1 to 20, according to the French grading system, where 1 to 9 constitutes a fail, and anything above 10 a pass. In general, a grade of 16 or above is rated as excellent, 14 to 15 as very good, 12 to 13 as good, and 10 to 11 as satisfactory. Each team had to read one of six books on management practices, relate the book to the material discussed in class, and finally present their findings in a group presentation. The group presentation was conveyed in a talk-show format in which participants were free to decide how to present their material in the most informative and entertaining manner. Participants were told beforehand that it is up to them to decide what information they choose to focus on and present. All team members received the same grade. Grades were determined, but not announced, just after each the presentation was completed.

\section{Results}

Variance partitioning of LC. Table 1 shows the SRM variance decomposition estimates for reports of LC. To facilitate interpretation, Table 1 reports the proportion of variance for each effect (i.e., actor, partner, and relationship). This is akin to estimating the ICC for each relevant random effect included in the model. Results indicated significant actor variance, $\sigma^{2}=.14$, Wald $z=$ $2.89, p<.01(95 \%$ confidence interval $[\mathrm{CI}]=[0.07,0.29])$, such that some people tended to stereotypically evaluate other people in a similar way. More importantly, significant partner variance was found, $\sigma^{2}=.18$, Wald $z=3.09$, $p<.01(95 \% \mathrm{CI}=[0.10,0.34])$, which was larger than the stereotypical ratings (i.e., actor variance). This indicates that several members of the groups reached a consensus concerning the leadership qualities of one or more fellow team members.

PLF and LC. PLF was significantly associated with LC, $t(23)=2.34, p<.05$ $(95 \% \mathrm{CI}=[0.04,0.59])$, using the SRM. Contrasting with these results, perceived fairness did not significantly predict LC using the standard deviation method of aggregation (see Table 2), whereas the parameter estimate for the 
Table I. Social Relations Model of Leadership Emergence for Working Groups in Study I $(N=38)$.

\begin{tabular}{lcccccc}
\hline Variable & $M$ & $S D$ & $\begin{array}{c}\text { Actor } \\
\text { variance } \\
\text { (assimilation) }\end{array}$ & $\begin{array}{c}\text { Partner } \\
\text { variance } \\
\text { (emergence) }\end{array}$ & $\begin{array}{c}\text { Relationship } \\
\text { variance }\end{array}$ & Error \\
\hline $\begin{array}{l}\text { Leader } \\
\text { consensus }\end{array}$ & 3.76 & 0.86 & $23 \% * *$ & $32 \% * *$ & $2 \%$ & $43 \%$ \\
\hline
\end{tabular}

Note. $k=204$ observations. Leadership emergence ratings were made on a scale ranging from I (not at all) to 5 (a great deal).

$* * p<.01$.

Table 2. Associations Between Different LC Estimates and Perceived Fairness and Group Performance for Study I $(N=38)$.

\begin{tabular}{lllc}
\hline & \multicolumn{3}{c}{ Leader consensus estimate } \\
\cline { 2 - 4 } & SRM & SD & Simple aggregation \\
\hline Perceived fairness & $0.32^{*}$ & 0.03 & $0.37^{* *}$ \\
Group performance & $1.01^{* *}$ & $3.62^{* *}$ & 0.19 \\
\hline
\end{tabular}

Note. Unstandardized estimates reported. SRM = social relations model.

$*_{p}<.05 . *_{p}<.01$.

association between perceived fairness and LC based on simple aggregation was positively and significantly related, $t(23)=3.57, p<.01(95 \% \mathrm{CI}=[0.16$, $0.57])$.

It is worth noting that the amount of variability explained by LC measured using SRM approach was $R_{(m)}^{2}=.11$, indicating a greater relative contribution in explaining LC compared with the previous significant model $\left(R^{2}=\right.$ .07). Furthermore, it is important to mention that the simple correlation between LC and perceived fairness of the partner was small in magnitude, $r=.27, p<.01$, indicating a small overlap between the tendency to be seen by others as a leader and the perceptions from others as a fair leader. Similarly, when the LC was correlated with the individual tendency to evaluate others as fair on average (actor effect), the correlation was nonsignificant, $r=-.07$, $p>.10$, indicating that fairness did not relate to LC as a result of continuity in judgments of the leader and her qualities, such as fairness.

LC and group performance. Results showed that LC predicted a significant amount of variance in group performance, $t(23)=3.21, p<.01, R^{2}=.23$, and that LC scores were positively and significantly associated with group 
performance, $b=1.01, p<.01$, using the SRM. Standard deviation scores of LC were also positively associated with group performance, $t(23)=4.09, p<$ $.01, R^{2}=.34$. Finally, using single aggregation method to estimate LC was not associated with group performance, $t(23)=0.59, p>.10$, to a statistically significant extent.

In sum, the SRM provided consistent and stable estimates of both perceived fairness and group performance compared with both methods of aggregation. In addition, the SRM estimates of LC were not shown to be highly correlated with measures of perceived fairness, indicating no overlap between the two constructs. Finally, using the SRM permitted us to disentangle the portion of variance corresponding to LC, allowing a high degree of confidence in the observed relationships.

\section{Study 2}

Study 1 was a preliminary test, which points out the utility of conceptualizing leadership as a measure of consensus. Study 1 also added relevant insights concerning the potential antecedents and consequences of LC. However, Study 1 employed a small sample size consisting of only a few groups; Study 1 also did not include relevant control variables which may help to explain the consensus phenomenon (i.e., personality explanation) or the link between LC and perceived justice and performance. Thus, we attempted to address these issues and expand on a more comprehensive model using a larger sample of participants in a second study. Study 2 extends the findings of Study 1 and properly estimates the mediational model anticipated in Hypothesis 3.

\section{Methodology}

Procedure and sample. As in Study 1, a sample of students working in project teams was used to assess the hypothesized mediational effect of LC on the relationship between PLF and team performance. Overall, the sample consisted of 194 participants (52\% female, $M_{\text {age }}=22.8$ years; $S D=4.4$ years). All students were part of an undergraduate business program. Thirty-five groups participated, each of which included four to seven members. Members were assigned to teams using random number assignment. Informed consent was provided to all participants; however, they were only told that the study was on the nature of team dynamics rather than specifically being told about the researchers' interest in fairness and leadership emergence to avoid any tendency toward social desirability bias when rating their peers for leadership qualities. Once the informed consent form was read, signed, 
and returned, we provided each team and student with an individual ID comprised of their team letter and individual number.

Measures. Members of each group reported their GPA and demographics at Time 1.

LC. As in Study 1 (Cronshaw \& Lord, 1987), participants were asked to evaluate each member of the team except themselves $(k=892$ independent observations). The internal consistency alpha was good $(\alpha=.95)$.

PLF. This scale was the same as administered in Study 1. Thus, participants scored their agreement with each item on a 7-point scale $(M=5.71$, $S D=1.52, \alpha=.91)$ ranging from 1 (strongly disagree) to 7 (strongly agree).

Team performance. It is better to use objective performance measures rather than simply rely on self-report surveys. Too high are the chances of contamination effects in the case of subjective ratings, which could include leniency effects or process-outcomes performance cuing effects (Martell \& Leavitt, 2002). In addition, using subjective performance ratings artificially strengthens the relationship between shared leadership and team performance outcomes (D'Innocenzo et al., 2016). Therefore, in Study 2, an independent third-party lecturer of the class assessed each team's performance.

Teams worked on a group project over the course of 16 weeks. Each team completed two to three group assignments over the course of one semester. Each assignment included both a paper and a presentation during normal class hours. The paper and presentation were graded separately, and group performance was based on the average of all group grades completed during the semester. Each team's performance was evaluated only based on this group work. Grades were assigned on a 100-point scale. Performance scores were determined at Time 2 but were not announced. Prior research demonstrates that grades are a meaningful measure of group performance (Hecht, Allen, Klammer, \& Kelly, 2002).

\section{Control variables}

Personality. The Big-Five personality dimensions questionnaire (Goldberg et al., 2006) was also administered to participants as a control variable when estimating potential antecedents of LC. Namely, openness to experience $(M=3.43, S D=0.56, \alpha=.75)$, conscientiousness $(M=3.45, S D=0.58$, $\alpha=.75)$, extraversion $(M=2.96, S D=0.65, \alpha=.78)$, agreeableness $(M=3.57, S D=0.53, \alpha=.70)$, and emotional stability $(M=2.85, S D=0.64$, $\alpha=.76$ ) were completed. Given that the study corresponded to a round-robin design, we introduced as control variables both personality dimensions of the 
perceiver as well as personality dimensions of the target (the person when evaluated by others).

Grades. We finally used GPA as control variable. For GPA $(M=3.31$, $S D=0.54$ ), we used the target average marking scores because we aimed to control for the potential impact of individuals perceived as leaders who were more (or less) successful in their marks on the average group performance. Age and gender of the target were also controlled for in the analyses.

Data analysis. As in Study 1, data analysis in the present study was conducted using an SRM for indistinguishable dyads (Kenny, 1994; Kenny \& Lavoie, 1984). Thus, random intercepts for actor, partner, dyad, and group were used to appropriately model the cross-classified data structure as a result of the round-robin design (Kenny \& Livi, 2009). PLF, age, and gender were introduced separately for the partner and the actor (i.e., pairwise data structure) so that actor and partner effects could be addressed as independent fixed effects.

The mediational analysis was performed using PROCESS (Hayes, 2013), a dedicated application used to conduct a large set of mediation and moderation analyses using bootstrapping. This analysis includes providing calculations for direct and indirect effect sizes, as well as confidence intervals and standard errors. The indirect effect was reported using the proportion of the total effect accounted for by the indirect effect (Wen \& Fan, 2015), and kappa-squared effect size (Preacher \& Kelley, 2011).

Before performing this analysis, we first estimated individual scores of LC based on the estimation of partner effect, following Kenny et al. (2006) formulas. In the present study, every individual rated each team member on leadership abilities and, therefore, each group member had the same opportunity to be perceived as a good leader. The associations tested were the degree to which one or more individuals were perceived as good leaders, partialling out the influence of other phenomena resulting from the process of mutual endorsement (Kenny et al., 2006).

\section{Results}

First, Pearson's correlations showed that correlations between the variables studied were not large in magnitude and mostly not statistically significant (see Table 3). This is especially relevant considering the cross-sectional nature of our data. Both Study 1 and Study 2 correspond to a multisource, round-robin design, which helps to partially address common method bias. However, it was important to determine whether our variable of justice in some way overlapped with our LC measure. That was not the case. Further 


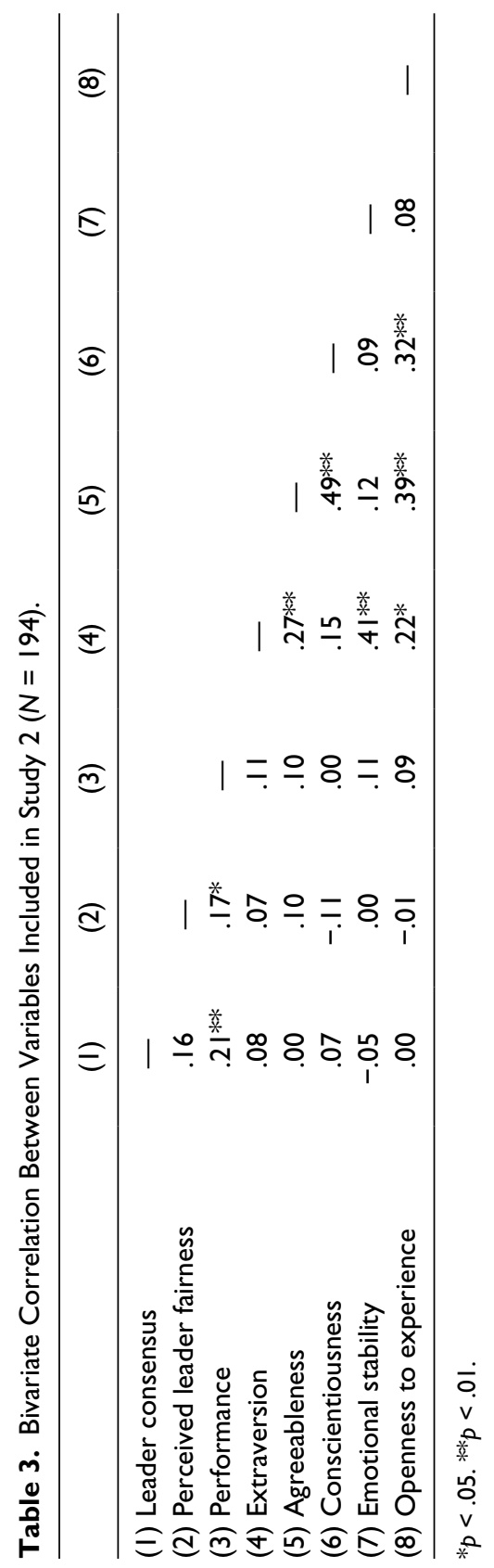


Table 4. Social Relations Model of Leadership Emergence for Working Groups in Study $2(N=194)$.

\begin{tabular}{lcccccc}
\hline Variable & $M$ & SD & $\begin{array}{c}\text { Actor } \\
\text { variance } \\
\text { (assimilation) }\end{array}$ & $\begin{array}{c}\text { Partner } \\
\text { variance } \\
\text { (emergence) }\end{array}$ & $\begin{array}{c}\text { Relationship } \\
\text { variance }\end{array}$ & Error \\
\hline Leadership & 3.48 & 1.29 & $40 \% * *$ & $34 \% * *$ & $15 \% * *$ & $11 \%$ \\
\hline
\end{tabular}

Note. $k=892$ observations. Leadership emergence ratings were made on a scale ranging from I (not at all) to 5 (a great deal).

$* * p<.01$.

results are separated into three subsections, following the three stages of analysis explained above.

Variance partitioning of $L C$. Table 4 shows the proportion of variance for each effect (i.e., actor, partner, and relationship). Results showed a significant actor variance, $\sigma^{2}=.54$, Wald $z=6.29, p<.01(95 \% \mathrm{CI}=[0.40,0.74])$. This indicates that some people assimilated group members as having the same degree of leadership or assigned equivalent ratings of leadership to all their fellow group members. Notably, significant partner variance exists, $\sigma^{2}=.48$, Wald $z=6.43, p<.01(95 \% \mathrm{CI}=[0.33,0.66])$. This indicates that group members generally agreed on the leadership qualities of specific members within groups. In other words, a certain amount of consensus emerged within groups concerning the leadership characteristics of some of their members.

This finding, once again, supports the idea that LC will significantly account for the degree of consensus in participants' ratings of leadership characteristics within each group. Results showed a significant amount of relationship variance, $\sigma^{2}=.15$, Wald $z=3.19, p<.01(95 \% \mathrm{CI}=[0.08,0.29])$, indicating that a certain degree of mutuality was observed between the leadership ratings among dyads. In other words, some consensus was reached regarding the leadership characteristics of other group members within each team.

Antecedents of $L C$. PLF was positively associated with $\mathrm{LC}, b=0.15, t(148)=$ $3.39, p<.01(95 \% \mathrm{CI}=[0.06,0.24])$. However, the variance explained by this fixed effect was small in magnitude, $R_{(m)}^{2}=.04$. Other control variables in the model (see Table 5) did not reveal any statistically significant effect. Overall, the findings suggest that the degree of leader fairness perceived by group members is consistently associated with LC.

Mediational process. In this analysis, we tested whether LC (estimated as partner effects) mediates the relationship between PLF and group performance. 


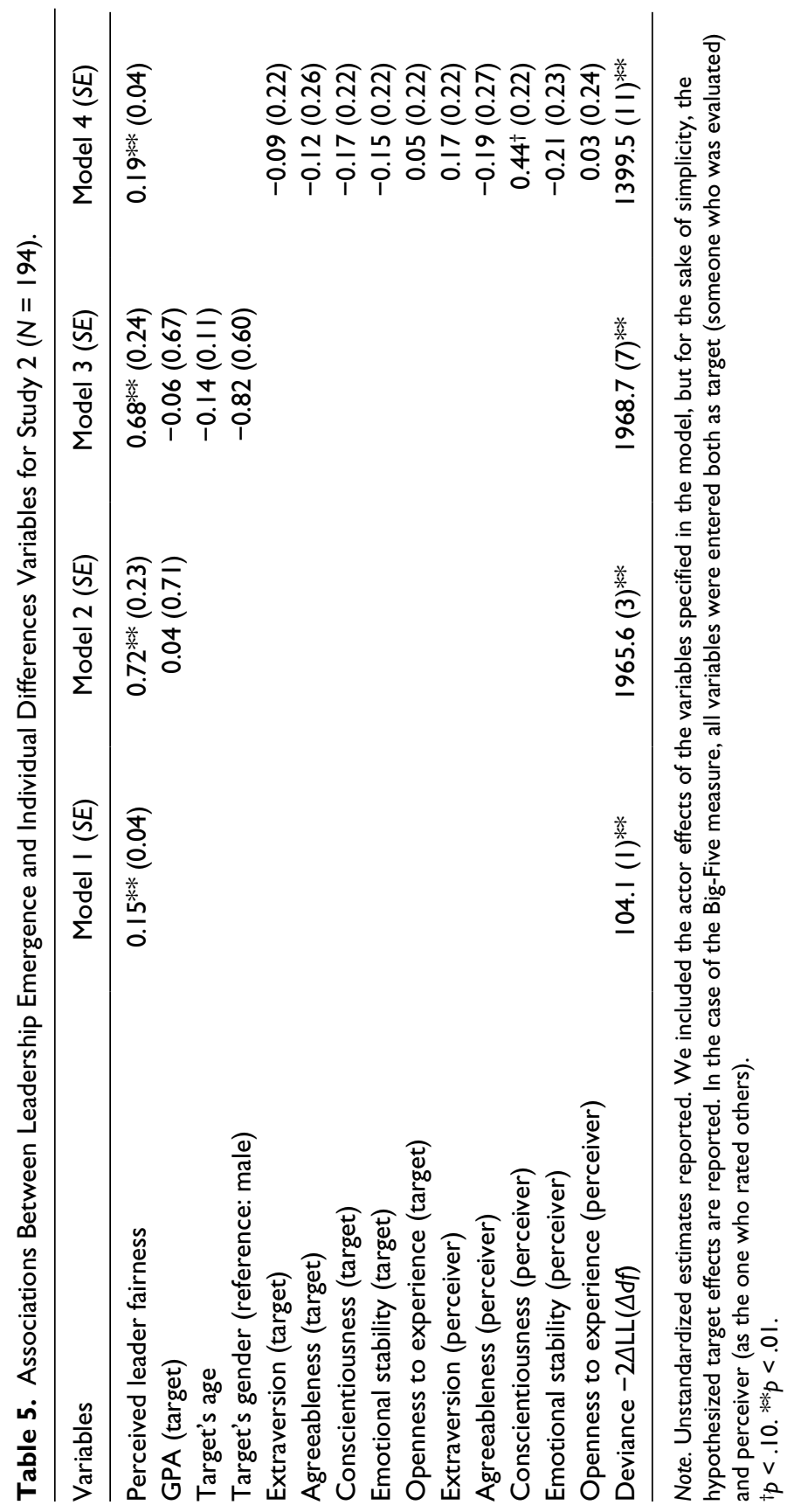




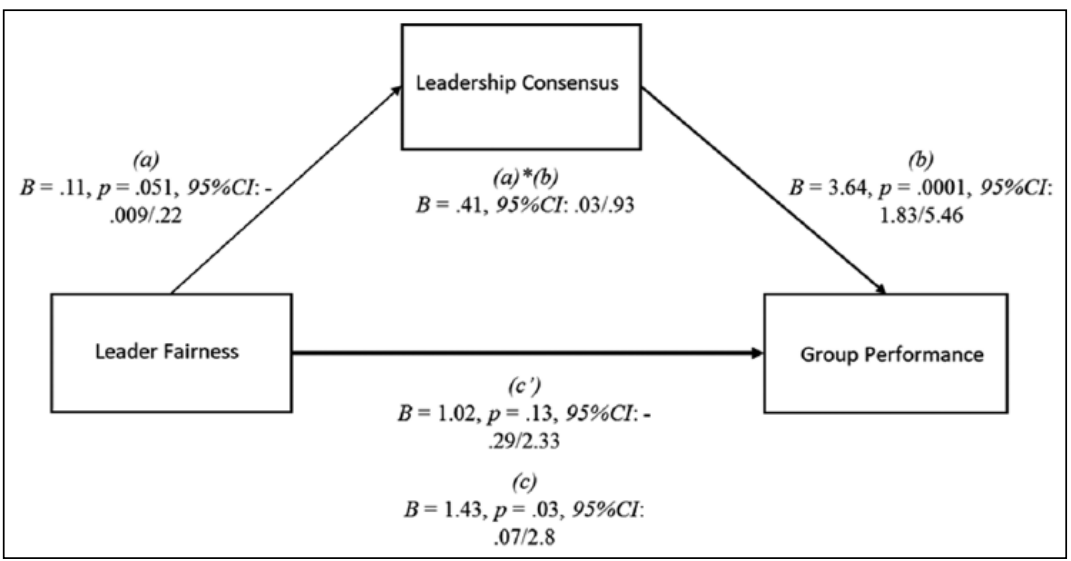

Figure I. Model for leader consensus mediating the relationship between perceived leader fairness and group performance in Study $2(N=194)$. Note. $\mathrm{Cl}=$ confidence interval.

Results from over 10,000 bootstrap re-samples yielded a significant total effect, $\beta=1.43, t(156)=2.09, p<.01(95 \% \mathrm{CI}=[0.08,2.78])$, indicating that PLF significantly predicted group performance. Once LC was included in the model, the direct effect of PLF fell below the minimum threshold for significance $(p=.13)$, and the indirect effect of PLF on group performance passing through LC was different from zero, $\beta=0.41(95 \% \mathrm{CI}=[0.03,0.92]), P_{M}=$ $0.29(95 \% \mathrm{CI}=[0.02,1.86]), k^{2}=0.05(95 \% \mathrm{CI}=[0.01,0.10])$. This provides evidence for a mediational process (the $95 \%$ confidence intervals did not include zero). This model also accounts for a significant amount of variance, $R^{2}=.12, F(2,155)=10.29, p<.01$. Thus, teams who perceived their leaders to be quite fair overall exhibited greater group performance as a result of the greater consensus on the positive leadership characteristics of the group leader, supporting Hypothesis 3. Figure 1 provides a graphical representation of these findings. The inclusion of age and gender in the model did not alter the main effects.

\section{Discussion}

The presented approach distinguishes individual differences in leadership from the mutual perceptions of leadership that each member endorses. Here, leadership qualities are not presumed from formal roles or static interpretations using unidirectional rates or inferences based on the aggregation of scores from pairs or triads of individuals. We endorse the SRM and a 
conceptualization of LC as a well-suited measure of leadership because SRM uses all possible mutual perceptions in a given group and then estimates the degree to which consensus is achieved with regard to leadership characteristics of one or more members. For this study, we therefore adopted a shared leadership view (Carson et al., 2007), which allowed us to address circumstances in which leadership is not always appointed but rather is socially constructed (DeRue \& Ashford, 2010; DeRue et al., 2015) and accounts for the fact that teams can have more than one leader (Vidyarthi, Erdogan, Anand, Liden, \& Chaudhry, 2014).

Recently, scholars have begun to accept leadership as more than the topdown, formal supervisory roles that were traditionally understood to be equivalent with leadership (Bedeian \& Hunt, 2006; DeRue \& Ashford, 2010). Likewise, previous literature describes cases in which formal supervisors are not perceived as leaders (Bedeian \& Hunt, 2006), whereas individuals with no supervisory power are perceived as leaders or leader-like by others (Charan, Drotter, \& Noel, 2011; Spreitzer \& Quinn, 2001). By defining leadership as a shared reality among the members of a given group, our research contributes to the idea that one or more members of the same group may spontaneously be perceived as the real leader of the team (DeRue \& Ashford, 2010). Therefore, we take a step back from the traditional perspective of leadership - that is, leadership is intrapersonal (individual characteristic), one-directional (leader exhibits authority over follower), and static (leaders will always be leaders and followers will always only be followers) - and instead conceptualize leadership as a process of mutual influence between leader and follower (DeRue \& Ashford, 2010). This allows us to view the leader-follower relationship as dynamic, and argue that this relationship can be reshaped and redirected over time depending on the situational context.

We propose a more sophisticated method to estimate the presence of LC among group member responses concerning leadership characteristics of team members. We define leadership based on the degree of consensus reached by individuals in groups based on the SRM, which provides a more robust and refined picture of leader-follower dynamics. This is in contrast to previous work on LC, which measured consensus by averaging group measures or standard deviations (Cole, Bedeian, \& Bruch, 2011). The findings indicate that group members reached consensus about their leadership, PLF was positively associated with LC, and that teams who perceived their leaders as fair exhibited higher group performance.

In keeping with previous studies, we evaluate the effect of one particular interpersonal characteristic predicting LC, namely, leader fairness. Our results show that members seem to put more effort into their work when they are treated fairly by a team leader to whose leadership they consent (Cohen, 
1992). In other words, team members are likely to follow others they deem worthy of being a team leader, if there is a strong consensus in the whole team. This reciprocation often translates into increased work performance, as demonstrated here in both studies by the significant and strong effect on group performance, which is mediated by consensus. Therefore, our findings indicate that leadership is a strong function of social perception processes occurring within groups. This further underlines the use of a consensus measure of leadership.

Regarding future research, we first advocate future studies to consider measures of consensus when evaluating the relationship between leadership and performance. We would like to encourage future researchers to use consensus as a meaningful expression of leadership within groups, particularly in organizational settings. One example could be found in organizations that utilize project teams, particularly when those teams are self-forming and selfmanaging. Additional research may also shed new light on these findings by increasing the number of teams involved in the study.

Second, future studies could investigate the reasons behind the perception of leadership, and subsequently the consensus on leadership. A possible research question could investigate the degree to which individuals differ in perceiving someone else as "leader-worthy." If individuals differ in their reasoning, we may be more inclined to support the conceptualization of leadership as an interpersonal recognized relationship (Shamir \& Eilam, 2005) rather than something that people "possess" (Hollander, 1993, p. 29), for example, specific traits, and so on. In contrast, if reasons for leader approval are similar, we may be more inclined to stick to traditional conceptualizations of leadership as an individual difference.

\section{Limitations}

This study has certain limitations. First, the observed groups consisted of students only. Antonakis, Ashkanasy, and Dasborough (2009) argued against using student samples, particularly because "the dynamics of social interaction and hence antecedents of success are not the same in student and realworld settings" (p. 249). In addition, Peterson (2001) shows that student samples were slightly more homogeneous than work samples and effect size sometimes differed in both size and direction in student samples compared with similar workplace samples. In contrast, Druckman and Kam (2009) argued for the use of student samples, calling for researchers to focus more on the issue of effects related to conceptualization, time, and context, rather than sample issues as obstacles to generalizability. They also recommend the use of dual samples of students and nonstudents, as well as a preference for experimentation over surveys (Druckman \& Kam, 2009). We agree that 
additional samples of nonstudents as well as further research based on experimental designs are needed to continue this line of research. Put differently, to generalize to organizational settings and to earn the genuine interest of the practitioner community, these findings should be replicated in organizational settings with practicing work teams. This marks an important limitation in this article.

Another critical point is the evaluation of the level of analysis used in this article. We would like to further elaborate on this point. As we mentioned in the article, implementing a round-robin design to evaluate leadership perception implies that the data structure is cross-classified, which means that there is not a unique Level 2 variable. Our partitioning variance method based on the SRM correctly identifies LC at Level 2, still preventing atomistic fallacy, which results from aggregating individual scores and interpreting this as a measure of the group. The SRM prevents conflation resulting from several of the previous methods used to estimate LC, as outlined in the article. Furthermore, we explained that a new variable was created to distinguish the effects (not the variances of the model) and this new variable was used to run the MLM models aimed to test the mediation model. This calculation is not simply an averaging of scores. The partner effect measure, or LC measure, controls for biases resulting from ignoring the different sources of variance when using interpersonal perceptions.

Should future scholarly work include the method displayed here, we emphasize using the Kenny et al. (2006) formula to compute a partner effect. This will be theoretically and empirically equivalent to what is called LC. Support for this can be found in Livi et al. (2008).

Third, we use MLM to estimate the corresponding variances. This method assumes that actor-partner covariance is zero and that dyadic covariance is positive. Although in the present research we mostly focus on partner variances, we had to make these strong assumptions regarding data analytic procedures, which, if not satisfied, may alter the magnitude, but not the significance, of the variance estimates.

Fourth, although we show that LC plays an important role as a predictor of group performance, we are limited by our measure of group performance. With regard to the measure in this study, we would like to point out, however, that all student data were collected using coded entries. In addition, the subjective scoring of group papers and presentations was conducted with no knowledge of the outcome of the surveys on leadership or justice. We are confident that external faculty members graded objectively and that this scoring method is sufficient to illuminate the relationships under examination here. To improve upon our findings, and with regard to future studies, we encourage researchers to use several external raters to evaluate projects' performance independently, before scores are tested for rater reliability as well. 
Finally, we also need to keep in mind that leader fairness is not a trait. As Lind et al. (2001) states, individuals' decision to help others or themselves is based on fairness judgments of their surroundings. Fairness is a set of trainable behaviors (Skarlicki \& Latham, 1996). It follows that leadership training and development seminars can have a great impact in shaping a leader's perceptions (Pierro, Giacomantonio, Kruglanski, \& van Knippenberg, 2014).

\section{Conclusion}

We suggest that LC reflects a meaningful shared leadership process because differences in leadership between individuals emerge as a result of consistencies in the mutual perceptions of team members regarding who is a leader. The present approach distinguishes individual differences in leadership from the mutual perceptions of leadership that each member endorses and uses this information as a key component that defines leadership. Our approach is a shared leadership process, as leadership qualities are not presumed from formal roles or static interpretations using unidirectional rates or inferences based on the aggregation of scores from pairs or triads of individuals. Based on the SRM, LC - as understood in the present approach - uses all the possible mutual perceptions in a given group and then estimates the degree to which consensus is achieved regarding the leadership characteristics of one or more members. We found that leader fairness predicts LC and group performance. Furthermore, the relationship between leader fairness and group performance was mediated by LC, that is, the degree of agreement of all team members on some positive leadership characteristics attributed to a particular team member. In closing, we recommend that additional research be undertaken in organizational settings and that future studies address the assumptions inherent in our study of partner effects.

\section{Acknowledgment}

The authors thank Dr. Annilee Game, Norwich Business School, for comments that greatly improved this article.

\section{Declaration of Conflicting Interests}

The author(s) declared no potential conflicts of interest with respect to the research, authorship, and/or publication of this article.

\section{Funding}

The author(s) received no financial support for the research, authorship, and/or publication of this article. 


\section{References}

Ambrose, M. L., \& Schminke, M. (2009). The role of overall justice judgments in organizational justice research: A test of mediation. Journal of Applied Psychology, 94, 491-500. doi:10.1037/a0013203

Anand, S., Hu, J., Liden, R. C., \& Vidyarthi, P. R. (2011). Leader-member exchange: Recent research findings and prospects for the future. In A. Bryman, D. Collinson, K. Grint, B. Jackson, \& M. Uhl-Bien (Eds.), The SAGE handbook of leadership (pp. 311-325). Thousand Oaks, CA: Sage.

Antonakis, J., Ashkanasy, N. M., \& Dasborough, M. T. (2009). Does leadership need emotional intelligence? Leadership Quarterly, 20, 247-261. doi:10.1016/j. leaqua.2009.01.006

Avolio, B. J., Jung, D. I., Murry, W., \& Sivasubramaniam, N. (1996). Building highly developed teams: Focusing on shared leadership processes, efficacy, trust, and performance. In M. M. Beyerlein, D. A. Johnson, \& S. T. Beyerlein (Eds.), Advances in interdisciplinary studies of work teams: Team leadership (Vol. 3, pp. 173-209). Greenwich, CT: JAI Press.

Back, M. D., \& Kenny, D. A. (2010). The social relations model: How to understand dyadic processes. Social \& Personality Psychology Compass, 4, 855-870. doi:10.1111/j.1751-9004.2010.00303.x

Bass, B. M. (1990). From transactional to transformational leadership: Learning to share the vision. Organizational Dynamics, 18, 19-31. doi:10.1016/0090-2616(90)90061-S

Bedeian, A. G., \& Hunt, J. G. (2006). Academic amnesia and vestigial assumptions of our forefathers. Leadership Quarterly, 17, 190-205. doi:10.1016/j. leaqua.2005.12.006

Brass, D. J. (1984). Being in the right place-A structural-analysis of individual influence in an organization. Administrative Science Quarterly, 29, 518-539. doi: $10.2307 / 2392937$

Brass, D. J., Galaskiewicz, J., Greve, H. R., \& Tsai, W. P. (2004). Taking stock of networks and organizations: A multilevel perspective. Academy of Management Journal, 47, 795-817. doi:10.2307/20159624

Burton, J. P., Sablynski, C. J., \& Sekiguchi, T. (2008). Linking justice, performance, and citizenship via leader-member exchange. Journal of Business and Psychology, 23(1-2), 51-61. doi:10.1007/s10869-008-9075-z

Carson, J. B., Tesluk, P. E., \& Marrone, J. A. (2007). Shared leadership in teams: An investigation of antecedent conditions and performance. Academy of Management Journal, 50, 1217-1234. doi:10.2307/AMJ.2007.20159921

Carter, D. R., \& Dechurch, L. A. (2012). Networks: The way forward for collectivistic leadership research. Industrial and Organizational Psychology-Perspectives on Science and Practice, 5, 412-415. doi:10.1111/j.1754-9434.2012.01470.x

Charan, R., Drotter, S., \& Noel, J. (2011). The leadership pipeline: How to build the leadership powered company (2nd ed.). San Francisco, CA: Jossey-Bass.

Cohen, J. (1992). A power primer. Psychological Bulletin, 112, 155-159. doi:10.1037/0033-2909.112.1.155 
Cohen-Charash, Y., \& Spector, P. E. (2001). The role of justice in organizations: A meta-analysis. Organizational Behavior and Human Decision Processes, 86, 278-321. doi:10.1006/obhd.2001.2958

Cole, M. S., Bedeian, A. G., \& Bruch, H. (2011). Linking leader behavior and leadership consensus to team performance: Integrating direct consensus and dispersion models of group composition. Leadership Quarterly, 22, 383-398. doi:10.1016/j. leaqua.2011.02.012

Colquitt, J. A., Scott, B. A., Rodell, J. B., Long, D. M., Zapata, C. P., Conlon, D. E., \& Wesson, M. J. (2013). Justice at the millennium, a decade later: A metaanalytic test of social exchange and affect-based perspectives. Journal of Applied Psychology, 98, 199-236. doi:10.1037/a0031757

Colquitt, J. A., \& Shaw, J. C. (2005). How should organizational justice be measured? In J. Greenberg \& J. A. Colquitt (Eds.), Handbook of organizational justice (pp. 113-152). Mahwah, NJ: Lawrence Erlbaum.

Contractor, N. S., DeChurch, L. A., Carson, J., Carter, D. R., \& Keegan, B. (2012). The topology of collective leadership. Leadership Quarterly, 23, 994-1011. doi:10.1016/j.leaqua.2012.10.010

Cronshaw, S. F., \& Lord, R. G. (1987). Effects of categorization, attribution, and encoding processes on leadership perceptions. Journal of Applied Psychology, 72, 97-106. doi:10.1037/0021-9010.72.1.97

Cropanzano, R., Prehar, C. A., \& Chen, P. Y. (2002). Using social exchange theory to distinguish procedural from interactional justice. Group \& Organization Management, 27, 324-351. doi:10.1177/1059601102027003002

Cullen, K. L., Palus, C. J., Chrobot-Mason, D., \& Appaneal, C. (2012). Getting to "we": Collective leadership development. Industrial and Organizational Psychology-Perspectives on Science and Practice, 5, 428-432. doi:10.1111/ j.1754-9434.2012.01475.x

Day, D. V., Gronn, P., \& Salas, E. (2004). Leadership capacity in teams. Leadership Quarterly, 15, 857-880. doi:10.1016/j.leaqua.2004.09.001

DeRue, D. S. (2011). Adaptive leadership theory: Leading and following as a complex adaptive process. Research in Organizational Behavior: An Annual Series of Analytical Essays and Critical Reviews, 31, 125-150. doi:10.1016/j.riob.2011.09.007

DeRue, D. S., \& Ashford, S. J. (2010). Who will lead and who will follow? A social process of leadership identity construction in organizations. Academy of Management Review, 35, 627-647. doi:10.5465/AMR.2010.53503267

DeRue, D. S., Nahrgang, J. D., \& Ashford, S. J. (2015). Interpersonal perceptions and the emergence of leadership structures in groups: A network perspective. Organization Science, 26, 1192-1209. doi:10.1287/orsc.2014.0963

D’Innocenzo, L., Mathieu, J. E., \& Kukenberger, M. R. (2016). A meta-analysis of different forms of shared leadership-team performance relations. Journal of Management, 42, 1964-1991. doi:10.1177/0149206314525205

Drescher, G., \& Garbers, Y. (2016). Shared leadership and commonality: A policy-capturing study. Leadership Quarterly, 27, 200-217. doi:10.1016/j .leaqua.2016.02.002 
Druckman, J. N., \& Kam, C. D. (2009). Students as experimental participants: A defense of the "narrow data base. In J. N. Druckman, D. P. Green, J. H. Kuklinski, \& A. Lupia (Eds.), Cambridge handbook of experimental political science (pp. 41-57). New York, NY: Cambridge University Press.

Ensley, M. D., Hmieleski, K. M., \& Pearce, C. L. (2006). The importance of vertical and shared leadership within new venture top management teams: Implications for the performance of startups. Leadership Quarterly, 17, 217-231. doi:10.1016/j. leaqua.2006.02.002

Erez, A., \& Isen, A. M. (2002). The influence of positive affect on the components of expectancy motivation. Journal of Applied Psychology, 87, 1055-1067. doi:10.1037/0021-9010.87.6.1055

Fletcher, J. K., \& Kaufer, K. (2003). Shared leadership: Paradox and possibility. In C. L. Pearce \& J. A. Conger (Eds.), Shared leadership: Reframing the hows and whys of leadership (pp. 21-47). London, England: Sage. doi:10.4135/ 9781452229539.n2

Folger, R. G., \& Cropanzano, R. (1998). Foundations for Organizational Science. Vol. 7: Organizational justice and human resource management. Thousand Oaks, CA: Sage.

Glynn, M. A., \& Raffaelli, R. (2010). Uncovering mechanisms of theory development in an academic field: Lessons from leadership research. Academy of Management Annals, 4, 359-401. doi:10.1080/19416520.2010.495530

Goldberg, L. R., Johnson, J. A., Eber, H. W., Hogan, R., Ashton, M. C., Cloninger, C. R., \& Gough, H. G. (2006). The international personality item pool and the future of public-domain personality measures. Journal of Research in Personality, 40, 84-96. doi:10.1016/j.jrp.2005.08.007

Graen, G. B., \& Graen, J. A. (Eds.). (2006). Sharing network leadership (Vol. 4). Greenwich, CT: Information Age.

Graen, G. B., \& Uhl-Bien, M. (1995). Relationship-based approach to leadership: Development of leader-member exchange (LMX) theory of leadership over 25 years: Applying a multi-level multi-domain perspective. Leadership Quarterly, 6, 219-247. doi:10.1016/1048-9843(95)90036-5

Gronn, P. (2002). Distributed leadership as a unit of analysis. Leadership Quarterly, 13, 423-451. doi:10.1016/S1048-9843(02)00120-0

Hayes, A. F. (2013). Introduction to mediation, moderation, and conditional process analysis: A regression-based approach. New York, NY: Guilford Press.

Hecht, T. D., Allen, N. J., Klammer, J. D., \& Kelly, E. C. (2002). Group beliefs, ability, and performance: The potency of group potency. Group Dynamics: Theory, Research, and Practice, 6, 143-152. doi:10.1037//1089-2699.6.2.143

Henderson, D. J., Liden, R. C., Glibkowski, B. C., \& Chaudhry, A. (2009). LMX differentiation: A multilevel review and examination of its antecedents and outcomes. Leadership Quarterly, 20, 517-534. doi:10.1016/j.leaqua.2009.04.003

Hoch, J. E., \& Kozlowski, S. W. (2014). Leading virtual teams: Hierarchical leadership, structural supports, and shared team leadership. Journal of Applied Psychology, 99, 390-403. doi:10.1037/a0030264 
Hollander, E. P. (1993). Legitimacy, power, and influence: A perspective on relational features of leadership. In M. M. Chemers \& R. Ayman (Eds.), Leadership theory and research: Perspectives and directions (pp. 29-47). San Diego, CA: Academic Press.

Janson, A., Levy, L., Sitkin, S. B., \& Lind, E. A. (2008). Fairness and other leadership heuristics: A four-nation study. European Journal of Work \& Organizational Psychology, 17, 251-272. doi:10.1080/13594320701746510

Judge, T. A., Bono, J. E., Ilies, R., \& Gerhardt, M. W. (2002). Personality and leadership: A qualitative and quantitative review. Journal of Applied Psychology, 87, 765-780. doi:10.1037//0021-9010.87.4.765

Kenny, D. A. (1994). Interpersonal perception: A social relations analysis. New York, NY: Guilford Press.

Kenny, D. A., Kashy, D. A., \& Cook, W. (2006). Dyadic data analysis. New York, NY: Guilford Press.

Kenny, D. A., \& Lavoie, L. (1984). The social-relations model. In L. Berkowitz (Ed.), Advances in experimental social psychology (Vol. 18, pp. 141-182). New York, NY: Academic Press.

Kenny, D. A., \& Livi, S. (2009). A componential analysis of leadership using the social relations model. In F. J. Yammarino \& F. Dansereau (Eds.), Research in Multi-Level Issues: Vol. 8. Multi-level issues in organizational behavior and leadership (pp. 147-191). London, England: Emerald Group. doi:10.1108/ S1475-9144(2009)0000008008

Lavelle, J. J., Rupp, D. E., \& Brockner, J. (2007). Taking a multifoci approach to the study of justice, social exchange, and citizenship behavior: The target similarity model. Journal of Management, 33, 841-866. doi:10.1177/0149206307307635

Lind, E. A., Kray, L., \& Thompson, L. (2001). Primacy effects in justice judgments: Testing predictions from fairness heuristic theory. Organizational Behavior and Human Decision Processes, 85, 189-210. doi:10.1006/obhd.2000.2937

Livi, S., Kenny, D. A., Albright, L., \& Pierro, A. (2008). A social relations analysis of leadership. Leadership Quarterly, 19, 235-248. doi:10.1016/j.leaqua.2008.01.003

Marion, R., \& Uhl-Bien, M. (2003). Complexity theory and Al-Qaeda: Examining complex leadership. Emergence, 5, 54-76. doi:10.1207/s15327000em0501_06

Marks, M. A., Mathieu, J. E., \& Zaccaro, S. J. (2001). A temporally based framework and taxonomy of team processes. Academy of Management Review, 26, 356-376. doi:10.5465/Amr.2001.4845785

Martell, R. F., \& Leavitt, K. N. (2002). Reducing the performance-cue bias in work behavior ratings: Can groups help? Journal of Applied Psychology, 87, 10321041. doi:10.1037/0021-9010.87.6.1032

Masterson, S. S. (2001). A trickle-down model of organizational justice: Relating employees' and customers' perceptions of and reactions to fairness. Journal of Applied Psychology, 86, 594-604. doi:10.1037/0021-9010.86.4.594

Masterson, S. S., \& Lensges, M. (2015). Leader-member exchange and justice. In T. N. Bauer \& B. Erdogan (Eds.), The Oxford handbook of leader-member exchange (pp. 67-86). New York, NY: Oxford University Press. doi:10.1093/oxf ordhb/9780199326174.013.0012 
Masterson, S. S., \& Tong, N. (2015). Justice perception formation in social settings. In R. S. Cropanzano \& M. L. Ambrose (Eds.), The Oxford handbook of justice in the workplace (pp. 291-308). New York, NY: Oxford University Press. doi:10.1093/oxfordhb/9780199981410.013.13

Mathieu, J. E., \& Chen, G. (2011). The etiology of the multilevel paradigm in management research. Journal of Management, 37, 610-641. doi:10.1177/ 0149206310364663

Mehra, A., Smith, B. R., Dixon, A. L., \& Robertson, B. (2006). Distributed leadership in teams: The network of leadership perceptions and team performance. Leadership Quarterly, 17, 232-245. doi:10.1016/j.leaqua.2006.02.003

Morgeson, F. P., DeRue, D. S., \& Karam, E. P. (2010). Leadership in teams: A functional approach to understanding leadership structures and processes. Journal of Management, 36, 5-39. doi:10.1177/0149206309347376

Nicolaides, V. C., LaPort, K. A., Chen, T. R., Tomassetti, A. J., Weis, E. J., Zaccaro, S. J., \& Cortina, J. M. (2014). The shared leadership of teams: A meta-analysis of proximal, distal, and moderating relationships. Leadership Quarterly, 25, 923942. doi:10.1016/j.leaqua.2014.06.006

Pearce, C. L., Conger, J. A., \& Locke, E. A. (2008). Shared leadership theory. Leadership Quarterly, 19, 622-628. doi:10.1016/j.leaqua.2008.07.005

Pearce, C. L., \& Sims, H. P. (2002). Vertical versus shared leadership as predictors of the effectiveness of change management teams: An examination of aversive, directive, transactional, transformational, and empowering leader behaviors. Group Dynamics: Theory, Research, and Practice, 6, 172-197. doi:10.1037//1089-2699.6.2.172

Pearce, C. L., Yoo, Y., \& Alavi, M. (2004). Leadership, social work, and virtual teams: The relative influence of vertical versus shared leadership in the nonprofit sector. In R. E. Riggio \& S. S. Orr (Eds.), Improving leadership in nonprofit organizations (pp. 180-203). San Francisco, CA: JosseyBass.

Peterson, R. A. (2001). On the use of college students in social science research: Insights from a second-order meta-analysis. Journal of Consumer Research, 28, 450-461. doi:10.1086/323732

Pierro, A., Giacomantonio, M., Kruglanski, A. W., \& van Knippenberg, D. (2014). Follower need for cognitive closure as moderator of the effectiveness of leader procedural fairness. European Journal of Work \& Organizational Psychology, 23, 582-595. doi:10.1080/1359432x.2013.781269

Podolny, J. M., Khurana, R., \& Hill-Popper, M. (2005). How to put meaning back into leading. HBS Working Knowledge. Boston, MA: Harvard Business School Press.

Preacher, K. J., \& Kelley, K. (2011). Effect size measures for mediation models: Quantitative strategies for communicating indirect effects. Psychological Methods, 16, 93-115. doi:10.1037/a0022658

Sanders, K., \& Schyns, B. (2006). Trust, conflict and cooperative behaviour: Considering reciprocity within organizations. Personnel Review, 35, 508-518. doi:10.1108/00483480610682262 
Schyns, B. (2006). Are group consensus in leader-member exchange (LMX) and shared work values related to organizational outcomes? Small Group Research, 37, 20-35. doi:10.1177/1046496405281770

Shamir, B., \& Eilam, G. (2005). “What's your story?” A life-stories approach to authentic leadership development. Leadership Quarterly, 16, 395-417. doi:10.1016/ j.leaqua.2005.03.005

Sivasubramaniam, N., Murry, W. D., Avolio, B. J., \& Jung, D. I. (2002). A longitudinal model of the effects of team leadership and group potency on group performance. Group \& Organization Management, 27, 66-96. doi:10.1177/ 1059601102027001005

Skarlicki, D. P., \& Latham, G. P. (1996). Increasing citizenship behavior within a labor union: A test of organizational justice theory. Journal of Applied Psychology, 81, 161-169. doi:10.1037/0021-9010.81.2.161

Spreitzer, G. M., \& Quinn, R. E. (2001). A company of leaders: Five disciplines for unleashing the power in your workforce. San Francisco, CA: Jossey-Bass.

Tyler, T. R., \& Lind, E. A. (1992). A relational model of authority in groups. Advances in Experimental Social Psychology, 25, 115-191. doi:10.1016/S00652601(08)60283-x

Uhl-Bien, M. (2006). Relational leadership theory: Exploring the social processes of leadership and organizing. Leadership Quarterly, 17, 654-676. doi:10.1016/j .leaqua.2006.10.007

Uhl-Bien, M., Graen, G. B., \& Scandura, T. A. (2000). Implications of leadermember exchange (LMX) for strategic human resource management systems: Relationships as social capital for competitive advantage. In G. R. Ferris (Ed.), Research in personnel and human resources management (Vol. 18, pp. 137-186). London, England: Emerald Group.

Uhl-Bien, M., \& Marion, R. (2008). Complexity leadership, Part 1: Conceptual foundations. Charlotte, NC: Information Age.

van Knippenberg, D., De Cremer, D., \& van Knippenberg, B. (2007). Leadership and fairness: The state of the art. European Journal of Work \& Organizational Psychology, 16, 113-140. doi:10.1080/13594320701275833

Vidyarthi, P. R., Erdogan, B., Anand, S., Liden, R. C., \& Chaudhry, A. (2014). One member, two leaders: Extending leader-member exchange theory to a dual leadership context. Journal of Applied Psychology, 99, 468-483. doi:10.1037/a0035466

Wang, D., Waldman, D. A., \& Zhang, Z. (2014). A meta-analysis of shared leadership and team effectiveness. Journal of Applied Psychology, 99, 181-198. doi: $10.1037 / \mathrm{a} 0034531$

Wen, Z., \& Fan, X. (2015). Monotonicity of effect sizes: Questioning kappasquared as mediation effect size measure. Psychological Methods, 20, 193-203. doi: $10.1037 /$ met0000029

Yammarino, F. J., Salas, E., Serban, A., Shirreffs, K., \& Shuffler, M. L. (2012). Collectivistic leadership approaches: Putting the "we" in leadership science and practice. Industrial and Organizational Psychology-Perspectives on Science and Practice, 5, 382-402. doi:10.1111/j.1754-9434.2012.01467.x 
Yukl, G. (2009). Leading organizational learning: Reflections on theory and research.

Leadership Quarterly, 20, 49-53. doi:10.1016/j.leaqua.2008.11.006

\section{Author Biographies}

Dritjon Gruda holds a dual PhD in Management and Psychology from EMLYON Business School, France, and Goethe University, Germany. He is currently a lecturer at Maynooth University in Ireland. In his research, he explores the role of individual differences in leadership perception.

Jim McCleskey is a course faculty member teaching in the MBA Program at Western Governors University, USA. His research areas include leadership, affect, emotional intelligence, and emotional labor.

Raul Berrios is an associate professor of Organizational Behavior at the University of Santiago, Chile. He holds a PhD from the University of Sheffield, England. His research interests intersect the study of emotions and interpersonal relationships at work, focusing on leadership, emotional complexity in the workplace, and goals theory. 